\title{
Integrated control of crown rot of banana with Candida oleophila strain 0 , calcium chloride and modified atmosphere packaging
}

\author{
Héloïse Bastiaanse ${ }^{\mathrm{a}}$, Luc de Lapeyre de Bellaire ${ }^{\mathrm{b}, \mathrm{c}}$, Ludivine Lassois ${ }^{\mathrm{a}}$, Coralie Misson ${ }^{\mathrm{a}}$, M. Haïssam Jijakli ${ }^{\mathrm{a}, *}$ \\ a University of Liège, Gembloux Agro-Bio Tech (GxABT), Plant Pathology Unit, Passage des Déportés 2, B-5030 Gembloux, Belgium \\ ${ }^{\mathrm{b}}$ CIRAD-PERSYST, UPR “Systèmes de cultures bananes, plantains et ananas", F-34398 Montpellier Cedex 5, France \\ ${ }^{\mathrm{C}}$ CARBAP, African Center for Research on Bananas and Plantains, Nyombé, Cameroon
}

\section{A R T I C L E I N F O}

\section{Article history:}

Received 17 June 2009

Accepted 23 October 2009

Available online 10 November 2009

\section{Keywords:}

Banana

Musa

Colletotrichum musae

Crown rot

Biological control

Candida oleophila

Calcium chloride

Modified atmosphere packaging

\begin{abstract}
A B S T R A C T
An integrated approach for biological control of crown rot of banana was studied. The efficacy of three control measures, applied alone or in various combinations, was evaluated under conditions highly conducive to the development of crown rot (artificial inoculation of Colletotrichum musae at $10^{4}$ conidia/ml). The studied measures were: application of an antagonistic yeast (Candida oleophila strain $\mathrm{O}$ at $1.10^{7} \mathrm{cfu} /$ $\mathrm{ml})$, treatment with $2 \%(\mathrm{w} / \mathrm{v})$ calcium chloride, and modified atmosphere packaging of fruit (MAP) in nonperforated polyethylene bags. C. oleophila was able to grow under MAP, maintaining a large population $\left(7.10^{6}\right.$ to $7.10^{7} \mathrm{cfu} / \mathrm{g}$ crown) throughout the 13 days of storage. Both treatment with the antagonistic yeast and storage under MAP, applied separately, reduced crown rot significantly (by $22 \%$ and $20 \%$, respectively, as compared to untreated controls). The effect of the yeast was the same whether it was produced in Petri dishes or in a fermentor. Calcium chloride treatment alone had no effect on C. musae. The antagonistic yeast showed a $16 \%$ higher biocontrol activity (from $26 \%$ to $42 \%$ ) when applied together with $2 \%(\mathrm{w} / \mathrm{v})$ calcium chloride, and the presence of this adjuvant made it possible to achieve the same protective effect with a lower yeast concentration. The highest efficacy (53\%) was achieved by the combination of the three alternatives means of control and a synergistic relation has been detected between the yeast, calcium chloride and MAP. Considering the severe conditions of screening, the consistency of the results obtained in this study indicates that the integrated strategy has great potential for control of crown rot of banana under commercial conditions.
\end{abstract}

(c) 2009 Elsevier Inc. All rights reserved.

\section{Introduction}

Crown rot is one of the most damaging postharvest diseases of exported bananas (Slabaugh and Grove, 1982; Reyes et al., 1998; Krauss and Johanson, 2000). It is caused by a large complex of fungal pathogens varying according to the geographic location and time of year (Meredith, 1971). Among the organisms composing this complex, Colletotrichum musae is often regarded as the most pathogenic (Greene and Goos, 1963; Lukezic et al., 1967; Shillingford, 1976; Finlay and Brown, 1993; Lassois et al., 2008). First symptoms may be observed after shipment, increasing rapidly during fruit ripening (Slabaugh and Grove, 1982). The rot begins at the cut surface of the crown and proliferates through the crown tissue, causing blackening and softening. In severe cases, the rot can spread through the pedicels of individual fingers and infect the banana pulp (Muirhead and Jones, 2000). This decay makes the fruit difficult to handle and unappealing to consumers, and a high incidence of crown rot can cause premature

\footnotetext{
* Corresponding author. Fax: +32 (0)81 610126.

E-mail address: MH.Jijakli@ulg.ac.be (M.H. Jijakli).
}

ripening during transit rendering the fruits unmarketable (Greene and Goos, 1963).

Control of crown rot of bananas involves an integrated combination of sanitation practices at field and packing station level, postharvest fungicide treatments and modified atmosphere packaging (MAP) (Slabaugh and Grove, 1982; Krauss and Johanson, 2000; Lassois et al., 2008). Despite these management practices, high crown rot levels are still encountered in the marketing of bananas. In the UK, for instance, losses exceeding $10 \%$ have been observed for fruits harvested in the Windward Islands during the rainy season (Krauss and Johanson, 2000). Furthermore, the increasing public demand for a strongly reduced pesticide use, stimulated by greater awareness of environmental and health issues, and the emergence of $C$. musae strains resistant to the key fungicides (Griffee and Burden, 1976; Johanson and Blazquez, 1992; de Lapeyre de Bellaire and Dubois, 1997), limit the postharvest application of chemicals to banana. Yet for banana from the Philippines, for example, losses as high as $86 \%$ have been recorded when the fruits were not subjected to any postharvest chemical treatment (Alvindia et al., 2000). These facts constitute a strong 
incentive to develop alternative strategies for the control of crown rot of banana.

The use of biological control agents (BCAs) for the management of postharvest diseases of fruits appears as a realistic approach for three main reasons: (i) the regulation of the environmental parameters during fruit storage is suitable for BCAs, (ii) the application sites of BCAs are limited to the fruit and (iii) the high retail value of fresh fruits can justify the potentially higher cost of biological treatments as compared to chemical methods (Wilson and Wisniewski, 1989; Janisiewicz and Korsten, 2002). Biological control of crown rot of banana has been evaluated with several BCAs, including notably fungi such as Glyocladium sp., Pythium sp., Trichoderma sp., Verticillum sp. (Krauss et al., 1998; East and Kenyon, 1998), bacteria of the Burkholderia cepacia complex (de Costa and Erabadupitiya, 2005) and several yeast strains of the species Rhodotorula glutinis, Cryptococcus laurentii and Cryptococcus albidus (Postmaster et al., 1997). A previous study identified Candida oleophila strain $\mathrm{O}$, a naturally occurring saprophytic yeast isolated from the surface of apple fruit (Jijakli et al., 1993b), as a promising agent for the control of crown rot of banana (Lassois et al., 2008). This strain was initially selected for its high and reliable antagonistic activity against Botrytis cinerea and Penicillium expansum, two important postharvest wound pathogens of apples (Jijakli et al., 1993b). Its potential as a BCA for use against crown rot of banana has been demonstrated on the basis of its antagonistic activity against an artificial fungal complex composed of $C$. musae, Fusarium moniliforme and Cephalosporium sp. In these experiments, the level of protection against the fungal complex appeared to depend on the incubation time before inoculation of the pathogens and on the fruit susceptibility to the fungal complex (Lassois et al., 2008). The highest protection level $(54.4 \%)$ was achieved when the strain was applied to crowns at the concentration of $10^{8}$ colony-forming units per milliliter (cfu/ml). Data also demonstrated an antagonistic activity of $C$. oleophila strain $\mathrm{O}$ against $C$. musae inoculated alone, with a protective level ranging from $33.4 \%$ to $47.2 \%$ at the concentrations tested $\left(10^{6}, 10^{7}\right.$ and $\left.10^{8} \mathrm{cfu} / \mathrm{ml}\right)$. Nevertheless, the biological treatments tested were always significantly less effective than the fungicide treatments.

Many BCAs provide a partial protection against postharvest diseases of many fruits, but most of them, when used alone, did not offer the level of control of synthetic fungicides. As biological means cannot currently solve all the problems of rots during fruit storage, they must be considered as a tool to be used in combination with other approaches in the framework of integrated disease management (Janisiewicz and Korsten, 2002). The combination of a BCA with organic and inorganic salts has been proposed as a safe and effective means of improving the biocontrol activity of the BCA against postharvest diseases of fruit. Prior studies have shown that the addition of calcium chloride improves the efficacy of $C$. oleophila against B. cinerea and Penicillium expansum on apple (McLaughlin et al., 1990; Jijakli et al., 1993a; Wisniewski et al., 1995), of Pichia guillermondii against rots of grapefruits (Droby et al., 1997) and of Aureobasidium pullulans against postharvest rots of sweet cherries (Ippolito et al., 2005). Improvement of biocontrol with additives may result from direct inhibition of the pathogen, elicitation of systemic acquired resistance in the host tissue and/or stimulation of the antagonistic activity. Moreover, since additives can make it possible to use a lower antagonist concentration without affecting the protection level (Lima et al., 2005), the presence of specific additives in the formulation of BCAs appears as an essential prerequisite to the commercial success of BCAs.

The successful commercial use of a BCA also depends on its compatibility with postharvest practices. Modified atmosphere packaging (MAP) of banana in non-perforated polyethylene bags called banavac is commonly used in international transport. Alteration of the gaseous environment, due to fruit respiration and spe- cific permeability of the plastic bags to gases, extends the storage life of bananas and maintains important quality attributes (Thompson, 1998). MAP of fruits in banavacs is also known to suppress spore germination and to reduce postharvest decay of bananas (Goos and Tschirsch, 1962; Slabaugh and Grove, 1982; Chillet and de Lapeyre de Bellaire, 1996; Thompson, 1998). By combining a BCA with calcium chloride and MAP of fruit it might be possible to overcome the shortcomings of each measure used separately and thus to obtain a satisfactory level of protection.

The present study was undertaken to develop an integrated strategy for controlling crown rot of banana, based on the combined use of the biocontrol agent $C$. oleophila strain $\mathrm{O}$, calcium chloride and fruit storage under MAP of fruit in 20- $\mu \mathrm{m}$-thick polyethylene banavacs. We first investigated the population dynamics of the antagonistic yeast during fruit storage under a reduced- $\mathrm{O}_{2}$, elevated- $\mathrm{CO}_{2}$ atmosphere, as the protective effect of $\mathrm{C}$. oleophila strain $\mathrm{O}$ seems to be closely related to its ability to colonize apples (Jijakli and Lepoivre, 1993). Next we tested some technological properties of $C$. oleophila strain $\mathrm{O}$, comparing the protective activity of the fresh yeast produced in a Petri dish with that of the lyophilized yeast produced in a fermentor. We then evaluated the efficacy of BCA, calcium chloride and MAP applied as stand-alone treatments and in combination under conditions highly conducive to the development of crown rot through artificial inoculation with C. musae.

\section{Materials and methods}

\subsection{Fruits}

Experiments were conducted with healthy-looking mature and unripe banana fruits (Musa acuminata AAA, cv Grande Naine, Cavendish subgroup) obtained (a) for monitoring the yeast population dynamics, from a commercial source in Belgium just before the ethylene treatment or (b) for the biocontrol assays, from the second and third hands of 20 bunches, just harvested at the same physiological age of 900 degree-days (Chillet et al., 2006) and collected in a packing shed in Cameroon (Dia-Dia, "Plantations du Haut Penja" PHP, Njombé).

For all experiments, hands were separated into 4-finger clusters, each randomly assigned to one assay modality. The external fingers on each hand were systematically eliminated. Smoothly cut crowns were obtained with a sharp knife leaving as much crown tissue as possible. Latex from crown tissue was dried with absorbent paper after $30 \mathrm{~min}$ and the crowns were surface-sterilized by submersion in $50 \%$ ethanol. The crowns were then dried during $2 \mathrm{~h}$ at ambient temperature before use.

\subsection{Microorganisms and chemical compounds}

Fifteen days before use, $C$. musae cultures were initiated from cryotubes (stored at $-20{ }^{\circ} \mathrm{C}$ in a $30 \%$ glycerol solution) by placing $100 \mu \mathrm{l}$ of suspension on a modified Mathur culture medium (per liter: $2.5 \mathrm{~g} \mathrm{MgSO}_{4} \cdot 7 \mathrm{H}_{2} \mathrm{O}, 2.7 \mathrm{~g} \mathrm{KH}_{2} \mathrm{PO}_{4}, 1 \mathrm{~g}$ peptone, $1 \mathrm{~g}$ yeast extract, $10 \mathrm{~g}$ sucrose, $15 \mathrm{~g}$ agar) at $25^{\circ} \mathrm{C}$ for 5 days. The culture was then transferred to fresh Mathur medium and incubated at $25^{\circ} \mathrm{C}$ for 10 days. The spore suspension was prepared by flooding the culture with sterile distilled water and filtering through a $45 \mu \mathrm{m}$ sieve. The concentration of the conidial suspension was determined with a Mallassez cell and adjusted to $10^{4}$ conidia/ml. The $C$. musae strain inoculated is sensitive to bitertanol and thiabendazole.

The antagonistic yeast $C$. oleophila strain $O$ was isolated from the surface of apple fruit (Jijakli et al., 1993b) and used at the concentration of (a) $10^{8} \mathrm{cfu} / \mathrm{ml}$ in order to monitor the yeast population dynamics or (b) $10^{7} \mathrm{cfu} / \mathrm{ml}$ in the three biocontrol experiments. 
Fresh yeast suspension was prepared from cultures on PDA at $25^{\circ} \mathrm{C}$ (cultures were transferred three times at 1-day intervals to fresh PDA medium before use) by flooding the cultures with sterile distilled water containing $8.5 \mathrm{~g} / \mathrm{l} \mathrm{NaCl}$. Final dilutions of the fresh $\mathrm{BCA}$ were adjusted with a Mallassez cell. In the biocontrol assays, two formulations of the BCA were tested: this fresh form and also a waterdispersible granule (WDG) formulation, named biomass in this study, obtained by growing the cultures in a fermentor and drying them in a fluidised bed dryer. The biomass suspension was prepared at $10^{7} \mathrm{cfu} / \mathrm{ml}$ as follows: $1 \mathrm{~g}$ biomass was rehydrated for $2 \mathrm{~h}$ with 31 of an $8.5 \mathrm{~g} / \mathrm{l} \mathrm{NaCl}$ solution.

For calcium chloride treatment, a $2 \%(\mathrm{w} / \mathrm{v})$ solution of dihydrated calcium chloride was used. Treatment with the fungicide bitertanol (Baycor ${ }^{\circledR}$ at $0.7 \mathrm{ml} / \mathrm{l}$ ) was used as the reference postharvest chemical control treatment.

\subsection{Preliminary evaluation of the yeast population dynamics on banana fruits under MAP}

The aim of this preliminary experiment was to ascertain that C. oleophila strain $\mathrm{O}$ can adapt to the changes in respiratory gas concentrations occurring during storage in banavacs. Crowns of each cluster were immersed for $10 \mathrm{~s}$ in a suspension of $C$. oleophila strain $O$ at $10^{8} \mathrm{cfu} / \mathrm{ml}$ prepared as previously described above. Fruits were packed in 18- $\mu$ m-thick perforated polyethylene bags or in $50-\mu \mathrm{m}$-thick non-perforated banavacs and then placed in commercial boxes. There were five commercial boxes per type of packaging and each box contained 10 fruit clusters. The size of each polyethylene bag was adjusted so as to have a constant ratio of plastic area to fruit weight $\left(0.15 \mathrm{~m}^{2} / \mathrm{kg}\right)$ and the fruits were stored at $13{ }^{\circ} \mathrm{C}$ for 10 days in order to simulate shipment. Then, to induce fruit ripening, the bananas were exposed for $24 \mathrm{~h}$ at $20{ }^{\circ} \mathrm{C}$, in hermetically sealed boxes, to azethyl gas (95\% $\mathrm{N}_{2}$ and $5 \%$ ethylene) at $1000 \mathrm{ppm}$, after which they were ventilated before storage for another 2 days at $20^{\circ} \mathrm{C}$. The yeast population was evaluated on one box of each packaging after 1, 2, 3, 10 and 13 days of storage. Crowns were explanted from the fruit with a sterile knife, weighed, immersed in 11 sterile $0.05 \mathrm{M}$ dibasic potassium phosphate buffer ( $\mathrm{pH}$ 6.5), and homogenized for $20 \mathrm{~min}$ at $120 \mathrm{rpm}$. Tenfold serial dilutions in sterile buffer were then prepared and yeast colonies were counted after transfer on a semi-selective medium composed of PDA supplemented with $12.5 \mathrm{mg} / \mathrm{l}$ hygromycine B, $0.25 \mathrm{mg} / \mathrm{l}$ Thiram and $2.5 \mathrm{mg} / \mathrm{l}$ Sumico. Four plates per dilution were poured with $100 \mu$ diluted suspension. After incubation at $25^{\circ} \mathrm{C}$ for 3 days, yeast colony counts were recorded and expressed as colony-forming units (cfu) per g of crown. Assays were performed three times.

\subsection{Evaluation of crown rot biocontrol by different postharvest treatments applied to fruits artificially inoculated with C. musae}

\subsubsection{Artificial inoculation, treatment, storage and ripening of fruits and rot evaluation}

Crowns were inoculated by placing $50 \mu$ of $C$. musae conidial suspension at the center of the freshly cut and sterilized surface. The droplet was immediately covered with a small paper filter. One hour after inoculation, the crowns of each cluster were immersed for $10 \mathrm{~s}$ in the assigned postharvest treatment bath. The 20 harvested bunches used in these experiments were treated statistically as blocks. Each treatment modality was applied to 20 clusters, one from each bunch. The clusters from each bunch were allotted randomly to the various modalities of each trial. One hour after the postharvest treatments, fruits were packed in perforated polyethylene bag (polybag) in commercial boxes. They were stored at $13{ }^{\circ} \mathrm{C}$ for 10 days in order to simulate shipment. Then, the bananas were dipped for a short time in a solution of Ethrel $(480 \mathrm{~g} / \mathrm{l})$ for ripening and placed at $20^{\circ} \mathrm{C}$ for 3 days. After these 13 days of storage, rot progression in the crown tissue was evaluated by cutting each crown longitudinally and measuring the area of the rot surface. This Internal Necrotic Surface (INS) was assimilated to a rectangle and measured in $\mathrm{mm}^{2}$.

\subsubsection{Effect of calcium chloride additive and yeast formulation on the biocontrol activity of $C$. oleophila strain $O$}

The first experiment was a preliminary evaluation of the ability of calcium chloride (2\%) to enhance the biocontrol activity of C. oleophila strain $\mathrm{O}$ against $C$. musae. Some technological properties of the antagonistic yeast were also tested, i.e. the level of protection against crown rot afforded by the antagonistic yeast grown in a Petri dish (fresh BCA) was compared with the level provided by the fermentor-grown, lyophilized, rehydrated yeast (the biomass suspension). In all, the experiment compared the efficacies of the following postharvest treatments applied to artificially inoculated clusters: (a) sterile distilled water, (b) fresh BCA, (c) biomass, (d) biomass + calcium chloride and (e) bitertanol solution $\left(\right.$ Baycor $\left.^{\circledR}\right)$. Assays were performed three times.

\subsubsection{Integrated biocontrol of crown rot with $C$. oleophila strain $O$, calcium chloride and MAP}

The efficacies of three postharvest treatments, the use of $C$. oleophila strain $\mathrm{O}$, the use of calcium chloride at $2 \%$ and storage of fruits under MAP were evaluated as stand-alone treatments and also in various combinations. The following treatments were applied on crowns artificially inoculated by C. musae: (a) sterile distilled water, (b) calcium chloride, (c) sterile distilled water + MAP, (d) calcium chloride + MAP, (e) biomass + MAP, (f) biomass + calcium chloride, (g) biomass + calcium chloride + MAP and (h) bitertanol solution $\left(\right.$ Baycor $\left.^{\circledR}\right)$. Fruits to be stored under MAP were packed in non-perforated polyethylene banavacs $(20 \mu \mathrm{m}$ thick). Fruits not to be stored under MAP were packed in perforated polyethylene bags ( $20 \mu \mathrm{m}$ thick). Assays were performed three times.

\subsubsection{Effect of calcium chloride and yeast concentration on the biocontrol activity of the antagonistic yeast $C$. oleophila strain $O$}

Calcium chloride at $2 \%$ was tested in combination with three concentrations of $C$. oleophila strain $\mathrm{O}$ : once, twice and four times the recommended concentration $\mathrm{n}$ (equal to $1 \mathrm{~g}$ biomass/3 $\mathrm{l}$ ). The following postharvest treatments were compared for crown rot control on artificially inoculated clusters: (a) sterile distilled water, (b) sterile distilled water + MAP, (c) biomass concentration $n+$ MAP, (d) biomass concentration $2 n+$ MAP, (e) biomass concentration $4 n+$ MAP, (f) biomass concentration $n+$ calcium chloride + MAP, (g) biomass concentration $2 n+$ calcium chloride + MAP, (h) biomass concentration $4 n+$ calcium chloride + MAP. Fruits to be stored under MAP were packed in non-perforated polyethylene banavacs ( $20 \mu \mathrm{m}$ thick), whereas fruits not to be stored under MAP were packed in perforated polyethylene bags $(20 \mu \mathrm{m}$ thick). Assays were performed three times.

\subsection{Data analysis}

On the basis of the enumeration of the yeast populations recovered from the banana clusters stored under different atmospheres, the Area Under Population Progress Curve (AUPPC) was calculated according to the equation of Campbell and Madden (1990):

$\mathrm{AUPPC}=\sum_{i}^{N-1}\left[\left(Y_{i}+Y_{i+1}\right) *\left(T_{i+1}-T_{i}\right)\right] * 0.5$

where $N$ is the number of evaluations, $Y$ the yeast population density in cfu/g crown and $T$ the number of days of storage. The AUPPC 
provides a convenient cumulative measure of the yeast population, and is used to average out the rate and shape of the yeast growth curve. The resulting AUPPC values were log transformed and subjected to analysis of variance (ANOVA) using MINITAB 13.1, the types of fruit packaging (2 levels) and storage length (5 levels) being used as fixed factors.

Data from the biocontrol experiments were factorially analysed by a three-way general linear model ANOVA using MINITAB 13.1 with treatment (5 or 8 levels depending on the biocontrol assay), repetition (3 levels) and bunch (20 levels) as main factors. The treatment means were separated at the $5 \%$ significance level by the Newman-Keuls test. To compare the effectiveness of the different postharvest treatments, INS were converted to protection level percentages (PLs) as follows: $\mathrm{PL}=\left[\left(D_{\mathrm{c}}-D_{\mathrm{t}}\right) / D_{\mathrm{c}}\right] * 100$, where $D_{\mathrm{c}}$ is the mean INS in the control and $D_{\mathrm{t}}$ is the mean INS corresponding to the treatment concerned.

To assess the advantage of combined postharvest treatments with respect to the same treatments applied alone, the type of interaction (additive, synergistic or antagonistic) was evaluated. For this the synergy factor (SF) was calculated according to the Abbott's formula (Levy et al., 1986): $\mathrm{SF}=Y_{\text {obs. }} / Y_{\text {exp. }}$, where $Y_{\text {obs. }}$. and $Y_{\text {exp., }}$ are, respectively, the observed and expected PLs of the combination. $Y_{\text {exp. }}$ was calculated as follows: $\left(Y_{\mathrm{a}}+Y_{\mathrm{b}}\right)-\left(Y_{\mathrm{a}} * Y_{\mathrm{b}} / 100\right)$, where $Y_{\mathrm{a}}=\mathrm{PL}$ of postharvest treatment $a ; Y_{\mathrm{b}}=\mathrm{PL}$ of postharvest treatment $b$. If $\mathrm{SF}=1$, the interaction between the two postharvest treatments is additive; if $\mathrm{SF}<1$, the interaction is antagonistic; if $\mathrm{SF}>1$, the interaction is synergistic.

\section{Results}

\subsection{Preliminary evaluation of the yeast population dynamics under MAP of fruits}

The population dynamics of yeast was very similar for the two types of packaging (Fig. 1). Population densities of C. oleophila strain $\mathrm{O}$ recorded on crowns increased from $7.10^{6} \mathrm{cfu} / \mathrm{g}$ crown soon after yeast application to a maximum of $2.10^{8} \mathrm{cfu} / \mathrm{g}$ crown after 10 days of storage at $13^{\circ} \mathrm{C}$. It decreased slowly after ethylene treatment. Log-transformed AUPPC values had equal variances and normal distributions. Analysis of variance of the AUPPCs indicated significant differences in the average population density on crowns between different times of evaluation during storage $(P<0.001)$.
No statistically significant differences $(P=0.729)$ were observed between the two types of packaging over the 13 days of storage. No significant interaction was detected between the factors "type of packaging" and "storage length" $(P=1.000)$.

\subsection{Effect of calcium chloride additive and yeast formulation on the biocontrol activity of $\mathrm{C}$. oleophila strain $\mathrm{O}$}

During this experiment, $C$. oleophila strain $\mathrm{O}$ was found to reduce significantly $(P<0.001)$ the INS by $22 \%$ in the case of the fresh yeast and by $26 \%$ in the case of the biomass suspension, as compared to the untreated control (Fig. 2). The difference observed between the biocontrol activities provided by the two forms of yeast was not statistically significant. Addition of calcium chloride (2\%) to the antagonist suspension significantly enhanced biocontrol. When the biomass suspension was used, calcium chloride addition caused the PL to increase by $16 \%$, from $26 \%$ to $42 \%$. Fungicide control of crown rot was stronger than any of the biological treatments tested (PL of 96\%).

\subsection{Integrated biocontrol of crown rot with $C$. oleophila strain $O$, calcium chloride and MAP}

Calcium chloride (2\%) as a stand-alone treatment (Fig. 3) was not effective against crown rot. All treatments in which the biomass suspension or MAP was used significantly reduced the INS $(P<0.001)$ as compared to the untreated control packed in perforated polyethylene bags. Furthermore, all treatments with the biomass suspension afforded a better protective level than the same treatment without it, except for the combination biomass + MAP. Under MAP, the PL was higher when $2 \%$ calcium chloride was included in the applied yeast cell suspension. Among the biological treatments, the best protection was provided by the combination of the BCA with calcium chloride and MAP (PL of 49\%). To ascertain the type of interaction (antagonistic, additive or synergistic) between calcium chloride and BCA, the data pertaining to the adjuvant-BCA combinations for fruit under MAP were further analyzed. BCA treatment and calcium chloride addition were found to act synergistically $(\mathrm{SF}=1.3$ ). Fungicide control of crown rot (PL of $99 \%$ ) remained stronger than control by any of the biological treatments tested.

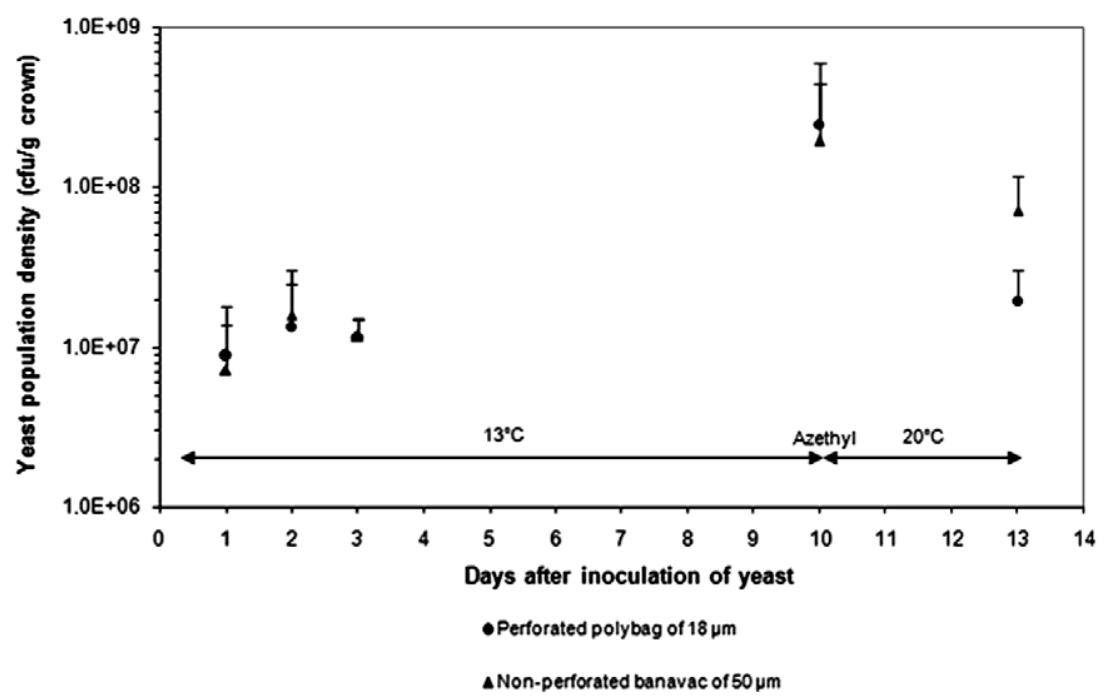

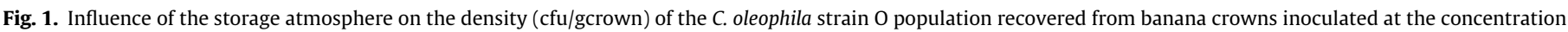

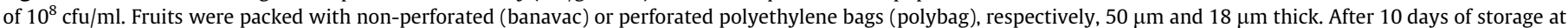

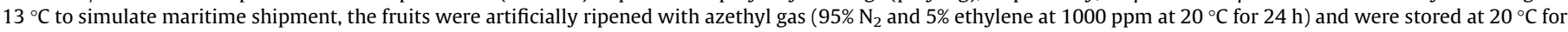
another 2 days. The population density data are means of three trials (10 clusters/trial). Bars represent standard deviations from the mean. 


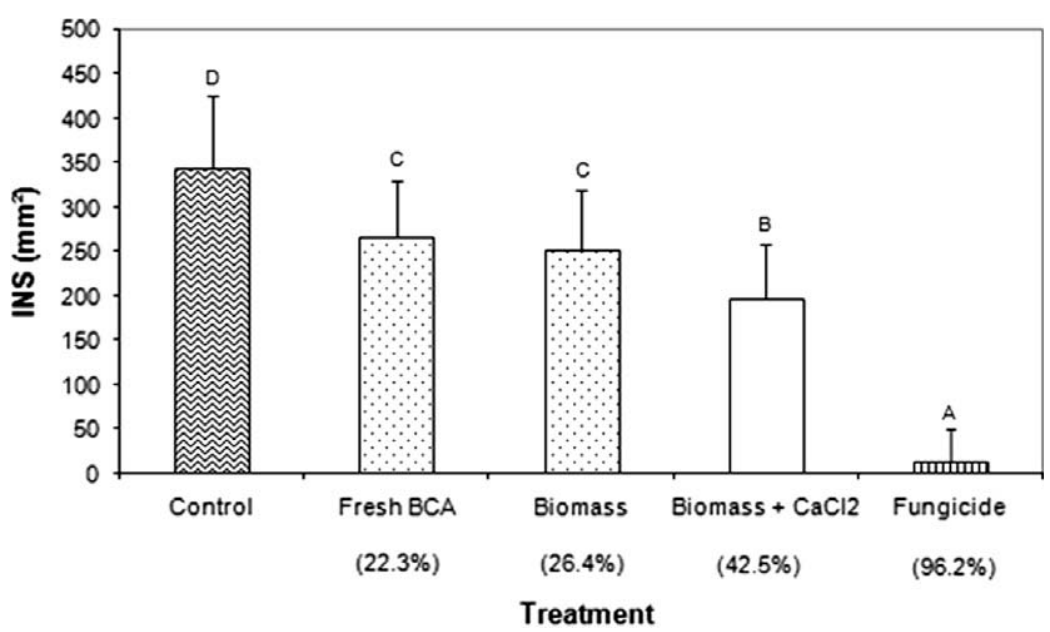

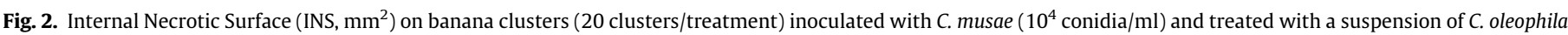

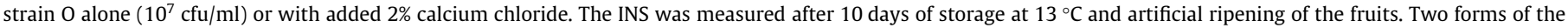

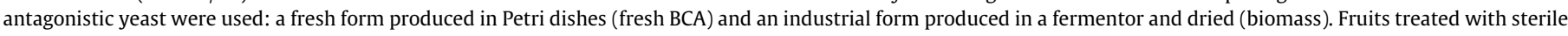

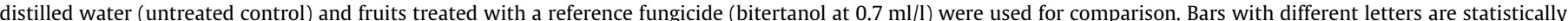

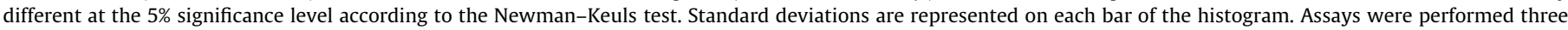
times.

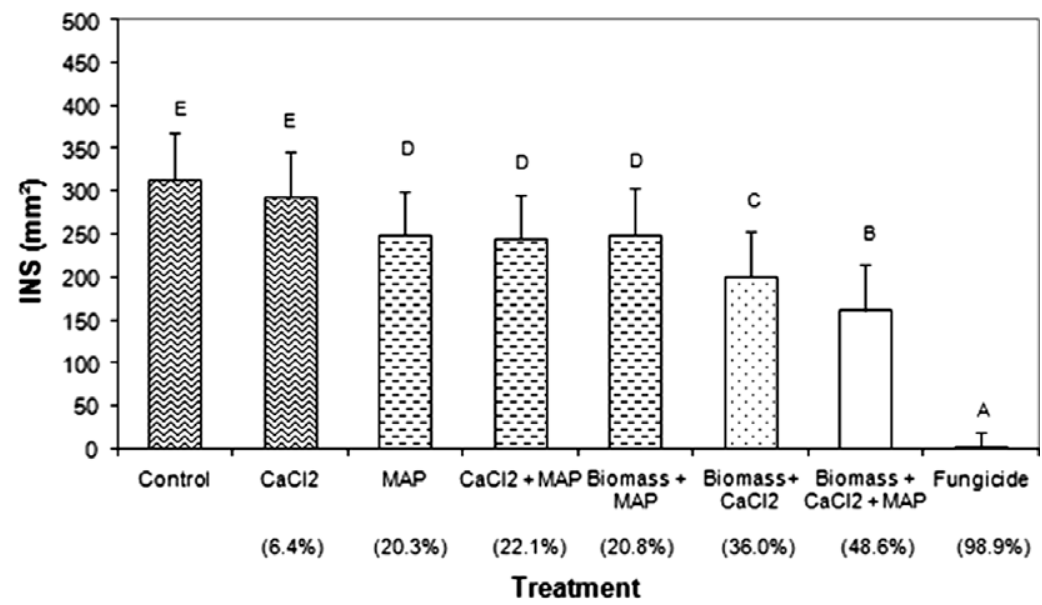

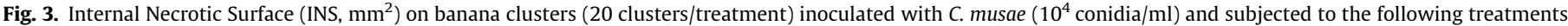

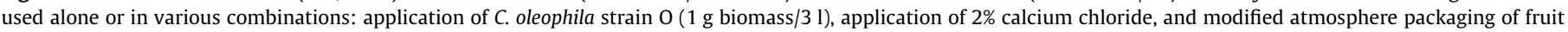

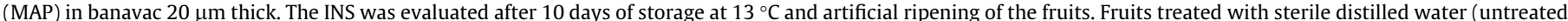

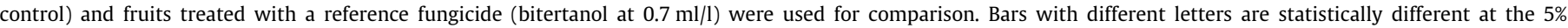
significance level according to the Newman-Keuls test. Standard deviations are represented on each bar of the histogram. Assays were performed three times.

\subsection{Effect of calcium chloride and yeast concentration on the biocontrol activity of $C$. oleophila strain $O$}

All concentrations of the BCA used with MAP of fruit in non-perforated banavacs significantly reduced the crown rot severity as compared to the untreated control $(P<0.001)$. A dose-response relationship was observed (Fig. 4): whereas the single dose ( $n=1 \mathrm{~g} / 3 \mathrm{l}$ ) and the double dose $(2 n)$ of BCA showed statistically the same efficacy (with PLs of $36 \%$ and $32 \%$, respectively), the quadruple dose $(4 n)$ afforded significantly higher protection $(\mathrm{PL}=42 \%)$. As in the previous experiment, addition of $2 \%$ calcium chloride to the yeast suspension greatly enhanced the antagonistic activity: calcium chloride combined with the recommended yeast concentration had a higher efficacy than the yeast applied alone at the 4-fold-higher concentration. Furthermore, the response appeared to increase more sharply with the BCA concentration when calcium chloride was added to the yeast suspension. Biocontrol of crown rot by $C$. oleophila strain $\mathrm{O}$ was most effective when the BCA was applied at $2 \mathrm{~g} / 3 \mathrm{l}$ (dose $2 n$ ) or $4 \mathrm{~g} / 3 \mathrm{l}$ (dose $4 n$ ) in combination with $2 \%$ calcium chloride.

\section{Discussion}

The need for suitable alternatives to fungicides for the control of postharvest decay has prompted research aiming to devise an integrated control strategy combining various alternatives and having the same efficacy as fungicide treatments. The objective of the present study was to evaluate the feasibility of combined application of a BCA (C. oleophila strain $\mathrm{O}$ ), an adjuvant (calcium chloride) and a modified atmosphere packaging of fruit (MAP) for the biocontrol of crown rot of banana.

In our study, the postharvest application of $C$. oleophila strain $\mathrm{O}$ at the concentration of $10^{7} \mathrm{cfu} / \mathrm{ml}$ resulted in a significant reduction of crown rot caused by $C$. musae, with a protection level of $22 \%$. In a previous study by Lassois et al. (2008) in which this 


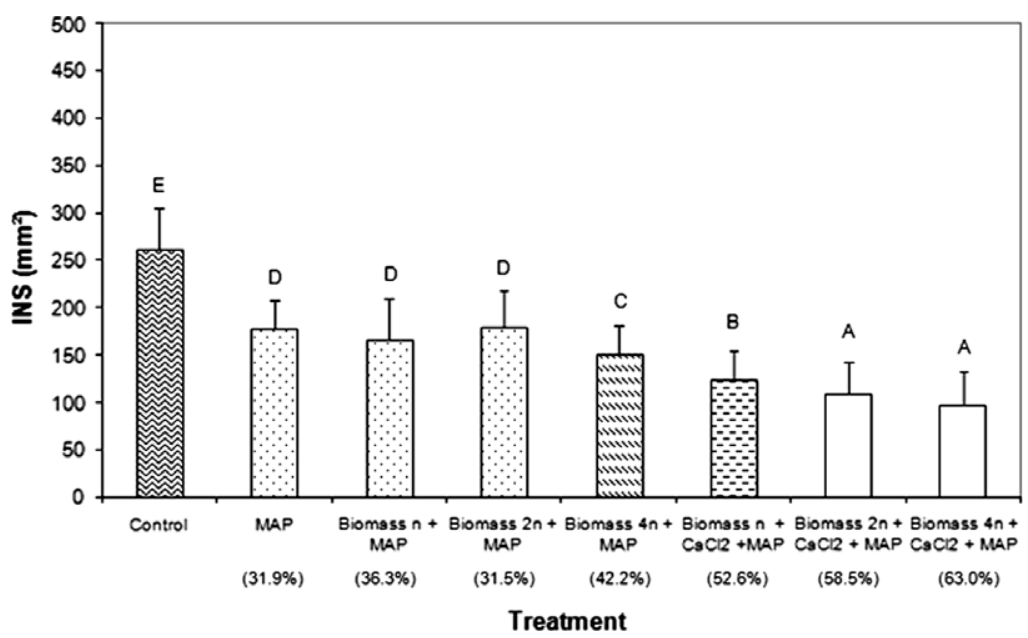

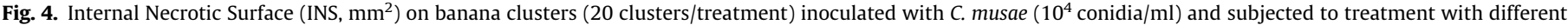

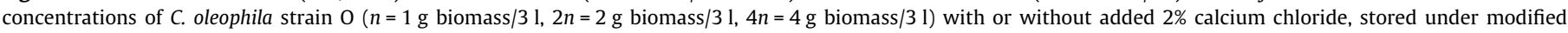

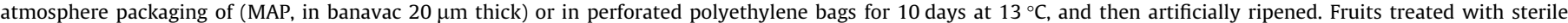

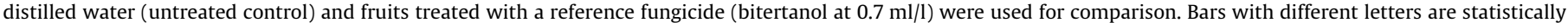

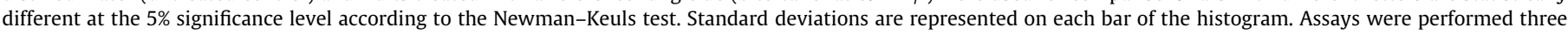
times.

yeast strain was used fresh, at the same concentration, on crowns artificially inoculated with $C$. musae, the protection level observed was $34 \%$, but the efficacy of the BCA was found to decrease when the severity of crown rot on the untreated control increased. Hence, the lower biocontrol activity observed in our study may be attributable to the greater severity of the disease observed on the untreated control (INS $=350 \mathrm{~mm}^{2}$ ) than in the previous study (INS $=270 \mathrm{~mm}^{2}$ ). Here we further show that $C$. oleophila strain $\mathrm{O}$ can be mass-produced and dried without affecting its efficacy against crown rot control, since the yeast produced in Petri dishes (fresh BCA) and the yeast produced in a fermentor, lyophilized and rehydrated prior to application (the biomass suspension) showed the same biocontrol activity. Although often neglected, this technological property constitutes an important selection criterion for candidate BCAs, since mass production by fermentation is quick, efficient, and inexpensive and since subsequent drying makes a biological product easy to handle and store, these features making the BCA compatible with practical use on an industrial scale.

While calcium chloride (2\%) alone failed to reduce significantly the severity of crown rot caused by $C$. musae, the combination of C. oleophila strain $\mathrm{O}$ with calcium chloride $(2 \%)$ resulted in synergistically enhanced biocontrol activity (a 16\% higher PL than when the biomass suspension was applied alone). The ability of calcium chloride to improve the biocontrol activity of antagonistic yeasts against several postharvest diseases of fruits has been widely demonstrated (McLaughlin et al., 1990; Jijakli et al., 1993a; Droby et al., 1997; Tian et al., 2002; Ippolito et al., 2005), but the mechanisms involved are not fully understood. Various hypotheses take into account the complex interactions involving host resistance and the wound response as well as the antagonistic interactions between BCA and pathogens (McLaughlin et al., 1990; Conway et al., 1994; Droby et al., 1997; Manganaris et al., 2005). Here, the fact that calcium chloride applied alone had no significant effect suggests that the observed improvement of biocontrol activity may be mainly due to the interaction of calcium with the yeast at the crown surface rather than to enhancement of host resistance or direct inhibition of the pathogen. Further study is needed to see if the presence of calcium affects growth and survival of the yeasts at the crown surface or if it increases the antagonistic activity of yeast by stimulating certain yeast physiological processes.
MAP of fruits is commonly used in international transport, and combining this modern storage technique with biological control is worth considering. We have observed that when bananas are packaged in 50- $\mu \mathrm{m}$-thick non-perforated polyethylene banavacs, the $\mathrm{O}_{2}$ content ranges between $1 \%$ and $2 \%$ and the $\mathrm{CO}_{2}$ content between $5 \%$ and $7 \%$ (unpublished data). Here we show that C. oleophila strain $\mathrm{O}$ seems well adapted to these changes in respiratory gas concentration, since the population dynamics was the same whether the fruits were stored under MAP or under standard conditions: when the yeast was applied at $10^{8} \mathrm{cfu} / \mathrm{ml}$ concentration, its population size remained high, between $7.10^{6}$ and $7.10^{7} \mathrm{cfu} / \mathrm{g}$ crown, throughout the 13 days of storage. Massart et al. (2005) likewise report that Ultra Low Oxygen (ULO) conditions $\left(1.5 \% \mathrm{O}_{2}\right)$ do not affect survival of $C$. oleophila strain $\mathrm{O}$ at the apple fruit surface. Since competition for nutrients may play a role in antagonistic activity (Jijakli et al., 1999; Janisiewicz and Korsten, 2002; Sparado and Gullino, 2004), the ability of C. oleophila strain O to survive and multiply at the crown surface under a modified atmosphere seems encouraging when one envisages the integrated use of this yeast with a MAP of bananas in non-perforated banavacs or possibly under a controlled atmosphere. In the present study, MAP packaging in non-perforated 20 - $\mu$ m-thick polyethylene banavacs significantly reduced crown rot during storage $(\mathrm{PL}=20 \%)$. This ability of MAP to reduce postharvest decays of banana has been widely reported by different authors (Slabaugh and Grove, 1982; Chillet and de Lapeyre de Bellaire, 1996; Thompson, 1998). $\mathrm{O}_{2}$ depletion and/or $\mathrm{CO}_{2}$ enrichment in the polyethylene bags might directly inhibit the pathogen (Goos and Tschirsch, 1962) and/or indirectly reduce rotting because banana ripening and senescence are delayed under MAP (Chillet and de Lapeyre de Bellaire, 1996). Whatever the case may be, MAP appeared in the present study to exert only a limited protective effect against crown rot. This is probably because the respiratory gas levels attained under MAP in 20- $\mu$ m-thick non-perforated polyethylene banavacs $\left(\mathrm{O}_{2}\right.$, $12-15 \% ; \mathrm{CO}_{2} 1-2 \%$, unpublished data) are not adequate for optimal inhibition of the pathogen or alteration of fruit physiology. Previous studies have indeed shown that ultra low $\mathrm{O}_{2}(<1 \%)$ and high $\mathrm{CO}_{2}$ concentrations $(>15 \%)$ are necessary to inhibit germination of C. musae conidia (Goos and Tschirsch, 1962) and that the optimal atmosphere for banana storage is $1-2 \% \mathrm{O}_{2}$ and $7 \% \mathrm{CO}_{2}$ (Thompson, 1998). 
Under MAP, addition of calcium chloride to the yeast suspension appears essential to crown rot biocontrol. Although the antagonistic yeast adapts well to the changes in respiratory gas levels inside the banavacs, the protection level afforded by MAP and BCA together was no higher than that afforded by MAP alone. Yet under MAP, the addition of calcium chloride to the BCA suspension was found to reinforce the biocontrol activity in a synergistic manner. This suggests that a factor or factors other than nutrient competition may be involved in biocontrol activity. It would be interesting to compare the population dynamics of this BCA under MAP in the presence and absence of calcium chloride, relating the observed dynamics to the protective activity of the yeast. It seems probable, in particular, that the adjuvant might enhance the colonization of the crown surface in the first 3 days after the postharvest treatment.

The development of cost-effective biofungicides against postharvest diseases will require studying how BCA concentration and the presence of an adjuvant affect the biocontrol level. In the present study, biocontrol of crown rot by $C$. oleophila strain $\mathrm{O}$ was most effective when the BCA was applied with calcium chloride at $4 \mathrm{~g}$ biomass/3 1 and the bananas were stored under MAP. Although a typical dose-response relationship was observed when the BCA dose was increased from $1 \mathrm{~g}$ biomass $/ 31$ (the recommended dose) to $4 \mathrm{~g}$ biomass $/ 3 \mathrm{l}$, the magnitude of the resulting PL increase cannot justify the additional cost inputs necessary to implement the treatment. Furthermore, application of $1 \mathrm{~g}$ biomass/ 31 with added calcium chloride afforded a better protective level than application of $4 \mathrm{~g} / 3 \mathrm{l}$ with no adjuvant (53\% vs. $42 \%$ ). An additional benefit of calcium chloride in yeast suspensions was the induction of a faster dose-response effect. When calcium chloride was added, a significant enhancement of the biocontrol activity was observed already at twice the recommended yeast dose, as opposed to 4 times the recommended dose in the absence of calcium chloride. Calcium chloride thus has potential in the framework of developing a cost-effective biofungicide for crown rot control, as an adjuvant to be included in the formulation of $C$. oleophila strain O. Similar control of decay by combining several strains of Candida sp. with $1 \%$ or $2 \%$ calcium chloride has been observed in apple challenged with $B$. cinerea (McLaughlin et al., 1990).

Although all treatments in which the BCA was used significantly reduced crown rot of banana, their efficacy in reducing crown rot of banana was variable. Indeed the protection levels achieved by the biomass suspension were $27 \%$ and $30 \%$ in the two-first assays of experiment 3.2 and only $22 \%$ in the third assay under the same experimental conditions. Moreover, for the combined BCA and calcium chloride treatment, and for the integrated treatment of $\mathrm{BCA}$ with calcium chloride and MAP, the protection levels in all experiments ranged, respectively, from $29 \%$ to $46 \%$ and from $38 \%$ to $60 \%$. Discrepancies in the efficacy of BCA under controlled environments have been widely observed (Elson et al., 1997; Lima et al., 1999; Guetsky et al., 2001 and Lassois et al., 2008) and may have several causes. Previous report (Lassois et al., 2008) indicates that the efficacy of $C$. oleophila strain $O$ against crown rot is highly dependent on the level of disease incidence. In this study, the differences observed in the INS of the untreated control inoculated with $C$. musae (from 104 to $525 \mathrm{~mm}^{2}$ ) offer an explanation for the variability of disease suppression achieved by the BCA. The magnitude of disease suppression may also be influenced by various biological factors, including the existence of a refuge on the fruit surface that may protect some of the pathogen propagules from the influence of the biocontrol agent, and the degree to which the spatial distributions of the pathogen and the BCA readily coincide (Johnson, 1994). Finally, since the activity of most BCA seems to be highly responsive to environmental factors, relatively small changes in the environmental parameter settings used during banana storage may influence the biocontrol efficacy of $C$. oleophila strain $\mathrm{O}$ observed in our study. Indeed, previous report (Hannusch and Boland, 1996) showed that changes of $4{ }^{\circ} \mathrm{C}$ or $5 \%$ relative humidity of the storage atmosphere of beans produced dramatic changes in white mold suppression by various BCAs (from $25 \%$ to $100 \%$ ).

In the present work no alternative method, even application of the BCA and calcium chloride combined with storage under MAP, was ever as effective as synthetic fungicides. Nevertheless, one should take into account the severe disease conditions encountered in this study: the INS observed on the untreated controls ranged from 260 and $350 \mathrm{~mm}^{2}$. Under such conditions previous results have shown, for the same yeast used at higher concentration $\left(10^{8} \mathrm{cfu} / \mathrm{ml}\right)$ against an artificially inoculated fungal complex, a protection level ranging between $20 \%$ and 30\% (Lassois et al, 2008). Thus, the 49-53\% PL achieved here with a 10 -fold lower concentration of BCA combined with calcium chloride and MAP represents a considerable improvement. Furthermore, the crowns in this study were inoculated with $50 \mu$ l of a suspension containing $10^{4}$ C. musae conidia per milliliter C. musae suspension, a very selective test since $C$. musae is considered as the most pathogenic fungus of the crown rot complex (Greene and Goos, 1963; Lukezic et al., 1967; Shillingford, 1976; Finlay and Brown, 1993). The inoculation of $C$. musae alone in this study created more severe inoculation conditions than inoculation of a fungal complex, as demonstrated by Lassois et al. (2008), because of the natural antagonism existing among the different pathogens of the complex causing crown rot of banana. Consequently, the consistency of the results obtained with $C$. oleophila strain $\mathrm{O}$ combined with calcium chloride and MAP under conditions highly conducive to the development of crown rot indicates that this integrated biological control strategy has great potential as a means of control of crown rot of banana under conditions of natural contamination. Additional studies are needed to compare this strategy with the use of postharvest fungicides under conditions of natural contamination and throughout the export process, including the industrial ripening stage.

Practically speaking, an integrated approach including the use of yeast antagonist, calcium chloride and MAP seems to be implementable on a commercial scale. Calcium chloride and modified atmosphere packaging are readily available on the market. The antagonistic yeast $C$. oleophila strain $\mathrm{O}$ can be mass-produced by a rapid, efficient, inexpensive fermentation procedure. Furthermore, biological control of crown rot seems to be easy to integrate into packing sheds, where the fungicide treatments applied to crowns could be replaced with antagonist suspension to be applied to freshly cut crowns with the standard equipment of the producer.

\section{Acknowledgments}

We acknowledge the precious technical assistance of Oscar Nguidjo and Robert Dongmo of the CARBAP. We also wish to thank Adeline Gillet of the Applied Statistics, Computer Science and Mathematics Unit of the Agricultural University of Gembloux and Viviane Planchon, of the Biometry Unit of the Walloon Agricultural Research Centre of Gembloux for their assistance in the statistical interpretation of the data. The authors thank the "Plantations du Haut Penja" (PHP, Cameroon) for kindly supplying fruits for this study, in addition to general support and collaboration.

\section{References}

Alvindia, D.G., Kobayashi, T., Yaguchi, Y., Natsuaki, K.T., 2000. Symptoms and the 419 associated fungi of postharvest diseases on non-chemical bananas imported from the 420 Philippines. Japanese Journal of Tropical Agriculture 44, 87-93.

Campbell, C.L., Madden, L.V., 1990. Introduction to Plant Disease Epidemiology. Wiley, New York. 532 pp. 
Chillet, M., de Lapeyre de Bellaire, L., 1996. Elaboration de la qualité de la banane. Détermination de critères de mesure. Fruits 51, 317-326.

Chillet, M., Hubert, O., Rives, M.J., de Lapeyre de Bellaire, L., 2006. Effects of the physiological age of bananas on their susceptibility to wound anthracnose due to Colletotrichum musae. Plant Disease 90, 1181-1185.

Conway, W.S., Sams, C.E., Kelman, A., 1994. Enhancing the natural resistance of plant tissues to postharvest diseases through calcium applications. Horticultural Science 29, 751-754.

de Costa, D.M., Erabadupitiya, H.R.U.T., 2005. An integrated method to control postharvest diseases of banana using a member of the Burkholderia cepacia complex. Postharvest Biology and Technology 36, 31-39.

de Lapeyre de Bellaire, L., Dubois, C., 1997. Distribution of thiabendazole-resistant Colletotrichum isolates from Guadeloupe banana plantations. Plant Disease 81, 1378-1383.

Droby, S., Wisniewski, M.E., Cohen, L., Weiss, B., Touitou, D., Eilam, Y., Chalutz, E., 1997. Influence of $\mathrm{CaCl}_{2}$ on Penicillium digitatum, grapefruit peel tissue, and biocontrol activity of Pichia guilliermondii. Phytopathology 87, 310-315.

East, L., Kenyon, L., 1998. Development of biological control methods for postharvest rots of bananas. Proceedings of an International Conference British Crop Protection Council, Farnham (GBR). pp. 549-554.

Elson, M.K., Schisler, D.A., Bothast, R.J., 1997. Selection of microorganisms for biological control of silver scurf (Helminthosporium solani) of potato tubers. Plant Disease 81, 647-652.

Finlay, A.R., Brown, A.E., 1993. The relative importance of Colletotrichum musae as a crown-rot pathogen on Windward Island bananas. Plant Pathology 42, 67-74.

Goos, R.D., Tschirsch, M., 1962. Effect of environmental factors on spore germination, spore survival and growth of Gloeosporium musarum. Mycologia $54,353-366$.

Greene, G.L., Goos, R.D., 1963. Fungi associated with crown rot of boxed banana. Pythopathology 53, 271-275.

Griffee, P.J., Burden, O.J., 1976. Fungi associated with crown rot of boxed bananas in the Windwards Islands. Phytopathologische Zeitschrift 85, 149-156.

Guetsky, R., Shtienberg, D., Elad, Y., Dinoor, A., 2001. Combining biocontrol agents to reduce the variability of biological control. Phytopathology 91, 621-627.

Hannusch, D.J., Boland, G.J., 1996. Influence of air temperature and relative humidity on biological control of white mold of bean (Sclerotinia sclerotiorum). Phytopathology 86, 156-162.

Ippolito, A., Schena, L., Pentimone, I., Nigro, F., 2005. Control of postharvest rots of sweet cherries by pre- and postharest applications of Aureobasidium pullulans in combination with calcium chloride or sodium bicarbonate. Postharvest Biology and Technology 36, 245-252.

Janisiewicz, W.J., Korsten, L., 2002. Biological control of postharvest diseases of fruits. Annual Review of Phytopathology 40, 411-441.

Jijakli, M.H., Lepoivre, P., 1993. Biological control of postharvest Botrytis cinerea and Penicillium on apples. IOBC/WPRS Bulletin. Biological Control of Diseases 16, 106-110.

Jijakli, M.H., Choutka, C., Lepoivre, P., 1993a. Formulation and integrated use of two antagonistic yeasts to postharvest treatments against diseases on apples. In: Proceedings of an EC Workshop: Biological Control of Fruit and Foliar Disease pp.107-117.

Jijakli, M.H., Lepoivre, P., Tossut, P., Thonard, P., 1993b. Biological control of Botrytis cinerea and Penicillium sp. on post-harvest apples by two antagonistic yeasts. Mededelingen van de Faculteit van Landbouwkundige en Toegepaste Biologische Wetenschappen, Universiteit Gent 58, 1349-1358.

Jijakli, M.H., Lepoivre, P., Grevesse, C., 1999. Yeast species for biocontrol of apple postharvest diseases: an encouraging case of study for practical use. In: Mukerij, K.G., Chamola, B.P., Upadhyay, R.K. (Eds.), Biotechnological Approaches in Biocontrol of Plant Pathogens. Kluwer Academic, Plenum Publishers, New York pp. 31-49.

Johanson, A., Blazquez, B., 1992. Fungi associated with banana crown rot on fieldpacked fruit from the Windward Islands and assessment of their sensitivity to the fungicides thiabendazole, procloraz and imazalil. Crop Protection 11, 79-83.
Johnson, K.B., 1994. Dose-response relationships and inundative biological control. Phytopathology 84, 780-784.

Krauss, U., Bidwell, R., Ince, J., 1998. Isolation and preliminary evaluation of mycoparasites as biocontrol agents of crown rot of banana. Biological Control 13, 111-119.

Krauss, U., Johanson, A., 2000. Recent advances in the control of crown rot of banana in the Windward Islands. Crop Protection 19, 151-160.

Lassois, L., de Lapeyre de Bellaire, L., Jijakli, M.H., 2008. Biological control of crown rot of bananas with Pichia anomala strain $\mathrm{K}$ and Candida oleophila strain $\mathrm{O}$. Biological control 45, 410-418.

Levy, Y., Benderly, M., Cohen, Y., Gisi, U., Bassand, D., 1986. The joint action of fungicides in mixture: comparison of two methods for synergy calculation. EPPO Bulletin 16, 651-657.

Lima, G., Arru, S., De Curtis, F., Arras, G., 1999. Influence of antagonist, host fruit and pathogen on the biological control of postharvest fungal diseases by yeasts. Journal of Industrial Microbiology and Biotechnology 23, 223-229.

Lima, G., Spina, A.M., Castoria, R., de Curtis, F., de Cicco, V., 2005. Integration of biocontrol agents and food-grade additives for enhancing protection of stored apples from Penicillium expansum. Journal of Food Protection 68, 2100-2106.

Lukezic, F.L., Kaiser, W.J., Martinez, M.M., 1967. The incidence of crown rot of boxed bananas in relation to microbial populations of the crown tissue. Canadian Journal of Botany 45, 413-421.

Manganaris, G.A., Vasilakakis, M., Mignani, I., Diamantidis, G., Tzavella-Klonari, K., 2005. The effect of preharvest calcium sprays on quality attributes, physiochemical aspects of cell wall components and susceptibility to brown rot of peach fruits (Prunus persica L. Cv. Andross). Scientia Horticulturae 107, 43-50.

Massart, S., De Clercq, D., Salmon, M., Dickburt, C., Jijakli, M.H., 2005. Development of real-time PCR using Minor Groove Binding probe to monitor the biological control agent Candida oleophila (strain O). Journal of Microbiological Methods $60,73-82$.

McLaughlin, R.J., Wisniewski, M.E., Wilson, C.L., Chalutz, E., 1990. Effect of inoculum concentration and salt solutions on biological control of postharvest diseases of apple with Candida sp. Phytopathology 80, 456-461.

Meredith, D.S., 1971. Transport and storage disease of bananas: biology and control. Tropical Agriculture 48, 35-50.

Muirhead, I.F., Jones, D.R., 2000. Postharvest diseases, abacá and enset. In: Jones, D.R. (Ed.), Diseases of bananas. CABI Publishing, pp. 190-211.

Postmaster, A., Kuo, J., Sivasithamparam, K., Turner, D.W., 1997. Interaction between Colletotrichum musae and antagonistic microorganisms on the surface of banana leaf discs. Scientia Horticulturae 71, 113-125.

Reyes, M.E.Q., Nishijima, W., Paull, R.E., 1998. Control of crown rot in "Santa Catarina Prata" and "Williams" banana with hot water treatments. Postharvest Biology and Technology 14, 71-75.

Shillingford, C.A., 1976. Occurrence of banana fruit-rot fungi in jamaican boxing plants. Plant Disease Reporter 60, 788-793.

Slabaugh, W.R., Grove, M.D., 1982. Postharvest diseases of bananas and their control. Plant Disease 66, 746-750.

Sparado, D., Gullino, M.L., 2004. State of the art and future prospects of the biological control of postharvest fruit diseases. International Journal of Food Microbiology 91, 185-194.

Thompson, A.K., 1998. Controlled Atmosphere Storage of Fruits and Vegetables. CAB International, Wallingford, UK.

Tian, S.P., Fan, Q., Jiang, A.L., 2002. Effects of calcium on biocontrol activity of yeast antagonist against the postharvest fungal pathogen Rhizopus stolinifer. Plant Pathology 51, 352-358.

Wilson, C.L., Wisniewski, M.E., 1989. Biological control of postharvest diseases of fruits and vegetables: an emerging technology. Annual Review of Phytopathology 27, 425-441.

Wisniewski, M., Droby, S., Chalutz, E., Eilam, Y., 1995. Effects of $\mathrm{Ca}^{2+}$ and $\mathrm{Mg}^{2+}$ on Botrytis cinerea and Penicillium expansum in vitro and on the biocontrol activity of Candida oleophila. Plant Pathology 44, 1016-1024. 